\title{
Synkinetic Spread and Hyperexcitability: Orbicularis Oris Recovery in Post-facial Synkinesis
}

\author{
Sinkinezik Yayılım ve Hipereksitabilite: Postfasiyal Sinkinezide Orbikülaris Oris \\ Toparlanmasi
}

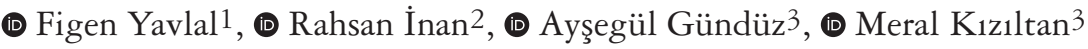 \\ 1Bahcesehir University Faculty of Medicine, Department of Neurology, Istanbul, Turkey \\ 2Kartal Dr. Lutfi Kirdar Training and Research Hospital, Clinic of Neurology, Istanbul, Turkey \\ 3Istanbul University-Cerrahpasa, Cerrahpasa Faculty of Medicine, Department of Neurology, Istanbul, Turkey
}

\begin{abstract}
Objective: Synkinesis after peripheral facial palsy is seen during spontaneous movements or reflex activity. The aim of the study was to investigate the recovery of the blink reflex (BR) R2-locked response on orbicularis oris (O.or) muscle, which is assumed to be caused by synkinetic spread of R2 recorded on orbicularis oculi (O.oc) in post-facial synkinesis.

Materials and Methods: A group of 20 patients who had post-facial synkinesis ( 5 males, 15 females and mean age: $38.1 \pm 18.0$ years) and 20 healthy individuals (9 males, 11 females and mean age: $42.7 \pm 11.8$ years) were included. Responses following single and paired electrical stimulations of the supraorbital nerve were recorded over bilateral O.oc in all participants and over O.or on the symptomatic side of patients. Latencies (for R1, R2 and R2-locked response on O.or) and area under the curve $[(\mathrm{AUC})$, for R2 and R2-locked response on O.or] were measured. Recovery rates of R2 and R2-locked responses recorded over O.or at interstimulus intervals of 200,600, and 1000 ms were calculated and compared.

Results: R1 and R2 latencies were longer and R2 AUC was smaller on the symptomatic side; however, the recovery rate of BR-R2 AUC was higher on the symptomatic side in the patient group. The recovery rate of R2-locked responses on O.or was also high and early, which was statistically similar to the recovery of R2.

Conclusion: In the presence of postparalytic facial syndrome, there is a R2-locked response on the O.or exhibiting high recovery rates similar to R2, suggesting a similar behavior and increased excitability of $\mathrm{O} .0 \mathrm{c}$ and O.or motoneurons or related circuits.
\end{abstract}

Keywords: Facial synkinesis, blink reflex recovery, orbicularis oris, R2-locked response

Öz

Amaç: Periferik yüz felci sonrası sinkinezi spontan hareket ya da refleks aktivite sırasında görülebilir. Göz kırpma refleksi (GKR) toparlanma süreci beyin sapındaki internöronların eksitabilitesini yansıtmaktadır. Çalışmanın amacı postfasiyal sinkinezi (PFS) olgularında orbikülaris oküli (O.ok) dışı bir kasta sinkinetik yayılım ile ortaya çıktığ1 varsayılan R2 uyumlu yanıtın toparlanmasını araştırmaktır.

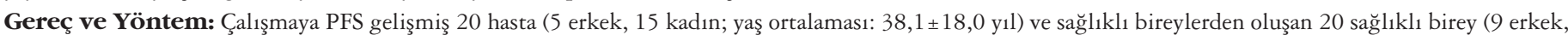
11 kadın; yaş ortalaması: $42,7 \pm 11,8$ yıl) alındı. Tüm katılımcılarda iki yanlı O.ok ve hasta grubunda semptomatik tarafta orbikülaris oris (O.or) kaslarından yüzeyel elektrotlar ile supraorbital uyarı sonrası standart GKR kaydedildi. Erken ve geç yanıtların latans (R1,R2 ve O.or 'deki R2 uyumlu yanıtın) ve geç yanıtların alan değerleri ölçüldü. R2 alanlarının ve semptomatik tarafta O.or üzerinde çıkan R2 uyumlu yanıtın 200, 600 ve 1000 ms aralıklı ikili uyaran sonrası toparlanma yüzdeleri hesaplandı ve gruplar arasında karşılaştırıldı.

Bulgular: Hasta grubunda felçli tarafta R1 ve R2 latansları daha uzun, O.ok üzerinde elde edilen R2 alanı daha düşük saptanmasına karşın, R2 O.ok toparlanma yüzdeleri hasta grubunda felçli tarafta daha yüksekti. Hasta grubunda felçli tarafta O.or üzerinde elde edilen toparlanma yüzdesinin aynı taraf O.ok üzerinde elde edilene benzer olduğu dikkat çekiciydi.

Sonuç: PFS'de O.ok ve O.or kasları üzerinde kaydedilen toparlanma eğrileri ve dolayısıyla bu kasları innerve eden motor döngülerin eksitabilite değişiklikleri paralellikler göstermektedir.

Anahtar Kelimeler: Fasiyal sinkinezi, göz kırpma refleksi toparlanması, orbikülaris oris, R2 uyumlu yanıt

Address for Correspondence/Yazişma Adresi: Figen Yavlal MD, Bahcesehir University Faculty of Medicine, Department of Neurology, Istanbul, Turkey Phone: +90 2129793000 E-mail: figenyavlal@ hotmail.com ORCID: orcid.org/0000-0002-6710-511X

Received/Geliş Tarihi: 01.10.2019 Accepted/Kabul Tarihi: 05.10.2020

${ }^{\circ}$ Copyright 2020 by Turkish Neurological Society

Turkish Journal of Neurology published by Galenos Publishing House. 


\section{Introduction}

Postparalytic facial syndrome (PFS), which occurs following peripheral facial palsy (PFP), is a complication characterized by synkinesis, myokymia, and involuntary contractions on the affected half of the face (1). Among these findings, synkinesis is an involuntary movement of a muscle group caused by the voluntary contraction of another muscle group. It develops due to the abnormal synchronization of the muscles innervated by the facial nerve (2). Several hypotheses have been proposed to underly the abnormal synchronization. Given the diversity of clinical symptoms, it is highly probable that multiple pathophysiologic mechanisms are involved. These mechanisms include the ephaptic transmission of the axonal impulses, aberrant regeneration of the facial nerve fibers, synaptic reorganization in the facial nerve nucleus, alteration of axonal excitability properties, segmental and suprasegmental reorganization, and an increase in motor neuron excitability in the facial nucleus $(3,4,5,6,7,8,9,10)$.

Electrophysiologic methods can be used to investigate ephaptic transmission between different facial nerve branches or hyperexcitability of its circuit. Lateral spread or ephaptic transmission can be examined by synchronous recordings of responses over two facial muscles supplied by different facial nerve branches following stimulation of each branch separately $(11,12)$. Through the use of the blink reflex (BR), the excitability of its circuit or synkinetic spread on lower facial muscles after the supraorbital nerve stimulation has been studied $(13,14,15)$. The recovery curve obtained by paired stimulation shows the excitability changes in the related circuitry. The increase in the R2 excitability has been shown in the recovery phase of PFP, especially in patients exhibiting post-facial synkinesis or residual weakness $(16,17,18,19)$.

In the present study, we aimed to investigate the excitability changes in the motor pathways innervating the orbicularis oris (O.or) in patients who developed synkinesis after PFP. In other words, the aim was to observe whether the change in the motor pathway innervating orbicularis oculi (O.oc) was parallel to the changes in the excitability of the motor pathway innervating O.or in the presence of synkinetic movements between O.oc and O.or muscles. For this reason, we studied the recovery of the O.or response and BR recovery after paired supraorbital stimulation.

\section{Materials and Methods}

A total of 20 patients who developed synkinesis after PFP and 20 healthy individuals (control group) were included in the study. All subjects gave written informed consent and the protocol was approved by Bahcesehir University Clinical Research Ethics Committee (protocol number: 2019-06/08, date: 20.03.2019), which was conducted in accordance with the ethical standards set in the Declaration of Helsinki.

The groups were similar in terms of sex and age (Table 1$)$. The mean age of the patients at the onset of PFP was $31.0 \pm 19.2$ years, and the mean duration of synkinesis was $8.0 \pm 11.9$ years (Table 1). None of the participants in the study had any other movement disorder, extrapyramidal disorders or a history of hemifacial spasm. All patients with PFP enrolled in the study were treatment naïve; they neither used benzodiazepines nor were they treated with botulinum toxin.

\section{Method}

Electrophysiologic studies were performed using an 8-channel electromyogram (EMG) instrument [Neuropack $\Sigma$ MEB-9100 instrument (Nihon Kohden, Tokyo, Japan)]. The BR was recorded using the standard method using surface silver-silver chloride electrodes in the supine position. Responses were recorded over bilateral O.oc muscles in the control and patient groups and over the O.or muscles of the symptomatic side in the patient group. For O.oc and O.or recordings, the active electrodes were placed in the middle of the lower eyelid and inferior to the lower lip on the point that intersected the lateral third and medial third of the muscle, respectively, whereas the reference electrodes were placed $2 \mathrm{~cm}$ lateral to the rima oculi and inferior to the mouth angle, respectively $(14,15)$.

We first recorded bilateral facial nerve motor response using nasalis muscle.

\section{Blink Reflex}

BR responses were recorded from the O.oc and O.or muscles after an electrical stimulus at an intensity five times the perception threshold of the supraorbital region. The duration of the stimulus was $0.2 \mathrm{~ms}$. The lower and higher frequency filters were $20 \mathrm{~Hz}$ and $1 \mathrm{kHz}$. The sweep rate was set to $50 \mathrm{~ms}$, sensitivity was set to 50 or $100 \mu \mathrm{V}$.

\section{Recovery Excitability of Blink Reflex}

To calculate the percentage recovery of $\mathrm{BR}$, paired stimuli at the supraorbital regions were given at 200,600, 1000-ms interstimulus intervals (ISIs) and the responses to the first (conditioning) stimulus and the second (test) stimulus were recorded. To prevent reflex habituation, stimuli were given randomly with a pause of at least 1 minute between each recording. For each ISI, four separate pairs of stimuli were given and the responses were averaged.

\section{Data Analysis}

After a single stimulus, the latencies of R1 and R2 were determined by reading on the screen with the cursor. The $\mathrm{R} 2$ area under the curve (AUC) was obtained by measuring the width of the $\mathrm{R} 2$ response with the EMG cursor on the screen and reported in millivolt $\mathrm{x}$ milliseconds. We also determined the presence, latencies, and AUC of the R2-locked responses obtained over the O.or muscles on the symptomatic sides.

The percentage recovery of BR was calculated by dividing the AUC of the response after the second stimulus by the AUC of the response after the first stimulus (R2 AUC after test stimulus/ R2 AUC after conditioning stimulus). Similarly, the percentage recovery of the R2-locked responses obtained over the O.or muscles on the symptomatic sides were also calculated.

We calculated the degree of axonal damage using the following formula: the amplitude of facial nerve motor response on the symptomatic sides/the amplitude of facial nerve motor response on the asymptomatic side.

\section{Statistical Analysis}

Analysis of the data was performed using the SPSS for Windows, version 11.5 software package. The Shapiro-Wilk test was used to determine whether the distribution of continuous variables was close to normal. Descriptive statistics are expressed as mean \pm standard deviation or median (minimum - maximum) 
for continuous variables, and counts (n) and percentages (\%) for nominal variables.

Student's t-test was used to analyze the differences between the groups in terms of the mean values, and the Mann-Whitney U test was used to analyze the differences in terms of the median values. Nominal variables were analyzed using Pearson's chi-square test. The Wilcoxon signed-rank test was used in the following comparisons:

i. Percentage of R2 recovery on symptomatic sides vs. asymptomatic sides,

ii. Percentage of R2 recovery on symptomatic sides vs. percentage of R2-locked responses obtained over O.or muscles on symptomatic sides.

The results were considered statistically significant when $\mathrm{p}<0.05$. Correlations between continuous variables were performed using Spearman's rank correlation coefficient (Spearman's Rho). The following variables were assessed:

i. R1 and R2 latencies of O.oc and degree of axonal damage

ii. R1 and R2 latencies of O.oc on the symptomatic side and duration of synkinesis

iii. Percentage of R2 recovery on symptomatic side obtained over the O.oc or O.or muscles and duration of synkinesis

iv. Percentage of R2 recovery on symptomatic side obtained over O.oc or O.or muscles and degree of axonal damage

Bonferroni correction was performed to check for possible type 1 errors in all multiple comparisons.

\section{Results}

\section{Blink Reflex}

The $\mathrm{R} 1$ and $\mathrm{R} 2$ response latencies on the symptomatic side of the patient group were found to be significantly longer than those on the asymptomatic side and those in the control group (Table 2). The R2 AUC of the symptomatic side was significantly lower than that of the asymptomatic side in the patient group (Table 2).

In the patient group, following the supraorbital stimulation, a response over the O.or of the symptomatic side was obtained simultaneously with the $\mathrm{R} 2$ response (R2-locked O.or response) (Figure 1). The magnitude of the O.or response was similar to the

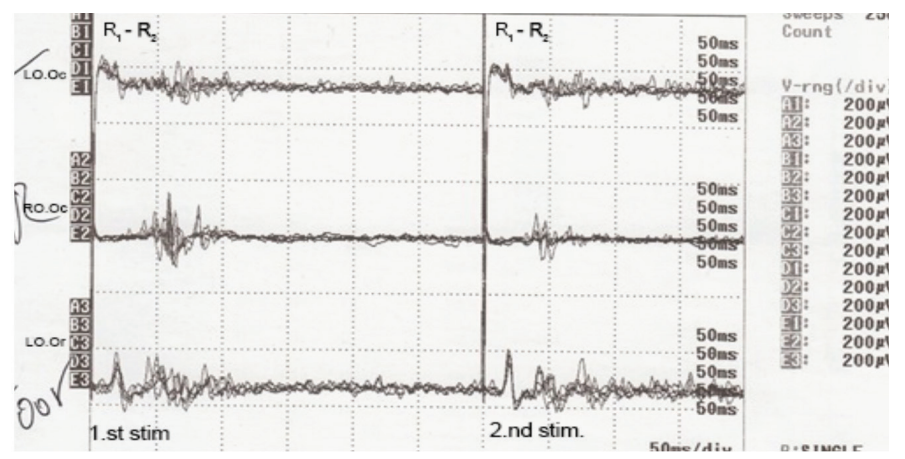

Figure 1. Example of R2- locked O.or response. Channels from top to bottom: symptomatic O.oc, asymptomatic O.oc and symptomatic O.or. Sensitivity: $200 \mu \mathrm{V} /$ div

O.or: Orbicularis oris, O.oc: Orbicularis oculi

\section{Table 1. The demographic characteristics of the patient and control groups}

\begin{tabular}{|c|c|c|c|}
\hline Variables & Control group $(n=20)$ & Patient group $(n=20)$ & $\mathrm{p}$ value \\
\hline Age (years) & $42.7 \pm 11.8$ & $38.1 \pm 18.0$ & $0.345^{\mathrm{a}}$ \\
\hline Age range (years) & $25-62$ & $14-69$ & - \\
\hline Male & $9(45.0 \%)$ & $5(25.0 \%)$ & - \\
\hline Female & $11(55.0 \%)$ & $15(75.0 \%)$ & - \\
\hline Age at time of PFP (years) & - & $31.0 \pm 19.2$ & - \\
\hline
\end{tabular}

Table 2. Blink reflex parameters after single supraorbital stimulation in the patient and control groups

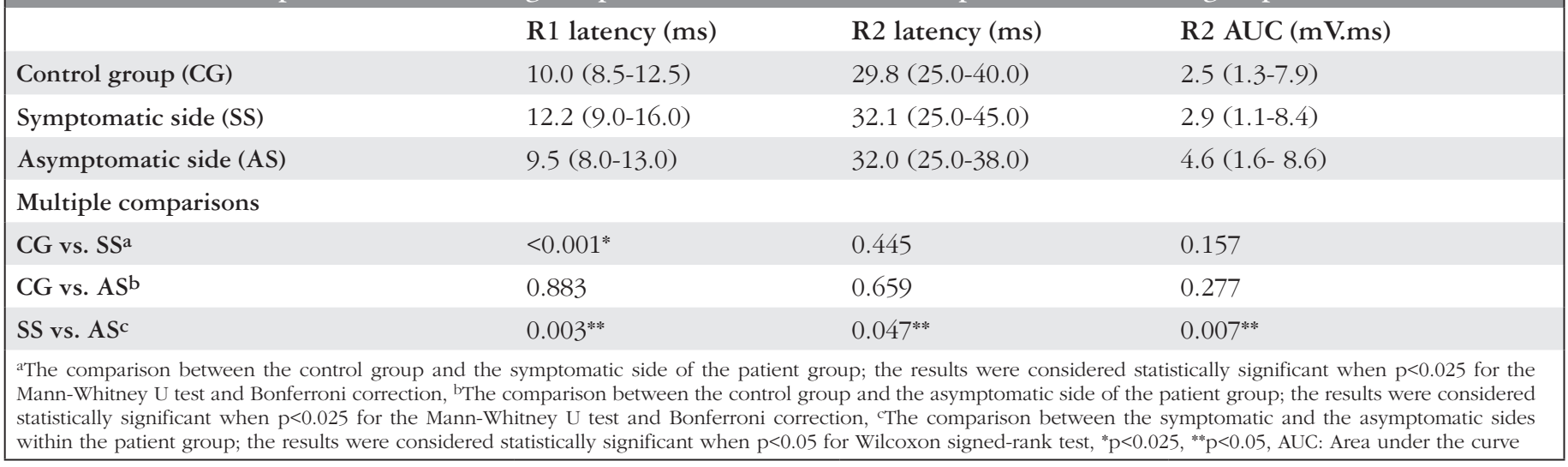


magnitude of $\mathrm{R} 2$ on the same side $(\mathrm{p}=0.709)$. The median $\mathrm{R} 2$ AUC of O.or response was 2.5 (range, 0.8-8.6) $\mathrm{mV}$.ms, while that for O.oc was $2.9 \mathrm{mV}$.ms (between 1.6-8.4 mV.ms). No correlation was found between R1 or R2 latencies of O.oc on the symptomatic and asymptomatic sides of the patient group and the degree of the axonal damage (rho: $-0.004, \mathrm{p}>0.05$ ). We found no correlation between the latencies and duration of synkinesis (rho: -0.052, $\mathrm{p}>0.05)$

\section{Recovery Excitability of Blink Reflex}

The percentage of $\mathrm{R} 2$ recovery at all ISIs were higher on the symptomatic side of the patient group in comparison with the asymptomatic side and with the control group. The percentage recovery at ISIs of $200 \mathrm{~ms}$ and $600 \mathrm{~ms}$ were significantly higher on the symptomatic side of the patient group compared with the control group (Table 3). However, only the difference at ISI of $600 \mathrm{~ms}$ was still significant after Bonferroni correction. BR recovery curves are shown in Figure 2A. In the patient group, the

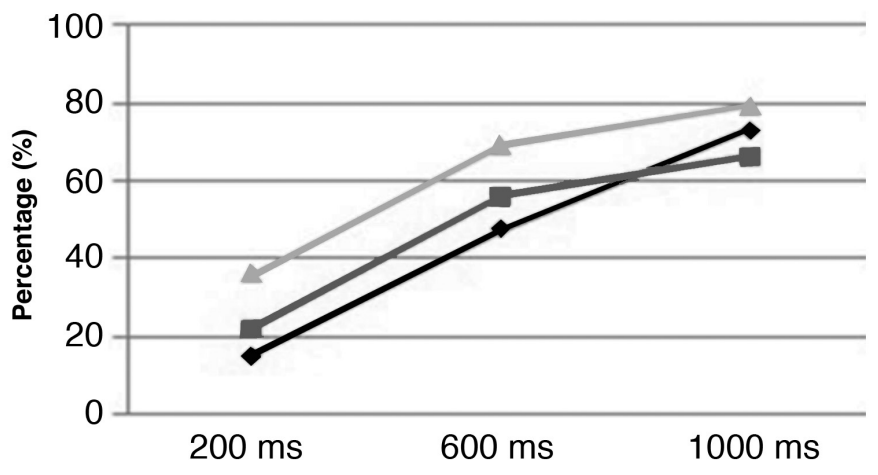

Figure 2A. Recovery curves of blink reflex-R2 responses on symptomatic sides (gray line) asymptomatic sides (dark gray line) of patients and healthy subjects (black line) percentage recovery of the O.or response on the symptomatic side was as high as the recovery rates recorded over the O.oc on the same side (Figure 2B). The comparisons of percentage recovery of responses obtained over the O.oc and the O.oc on the symptomatic side in the patient group revealed no significant differences (Table 3). No correlation was found between the recovery rates of the O.or or O.oc on the symptomatic side of the patient group and the degree of axonal damage (rho: $-0.007, \mathrm{p}>0.05$ ). No significant correlation was found between the percentage recovery and duration of synkinesis (rho: $-0.064, \mathrm{p}>0.05$ ).

\section{Discussion}

The main findings of our study were as follows: (i) there was a time-locked response on the O.or muscle on the symptomatic side identical to the latency and magnitude of the $\mathrm{R} 2$ response on the same side; (ii) the recovery of the R2-locked O.or response was significantly enhanced similar to the one obtained over the O.oc. In addition, similar to previous reports, the latencies of BR R1

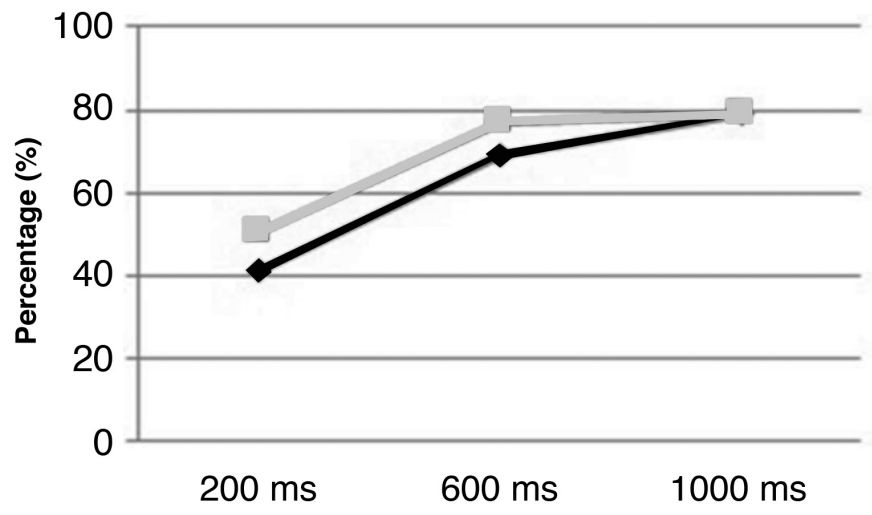

Figure 2B. Recovery rates at ISIs of $200 \mathrm{~ms}$ and $600 \mathrm{~ms}$ were high on symptomatic sides of patients. Recovery curves of blink reflex-R2 responses (black line) and R2-locked response on orbicularis oris (gray line) on symptomatic sides

ISIs: Interstimulus intervals

Table 3. R2 AUC and AUC of O.or response in the patient and control groups

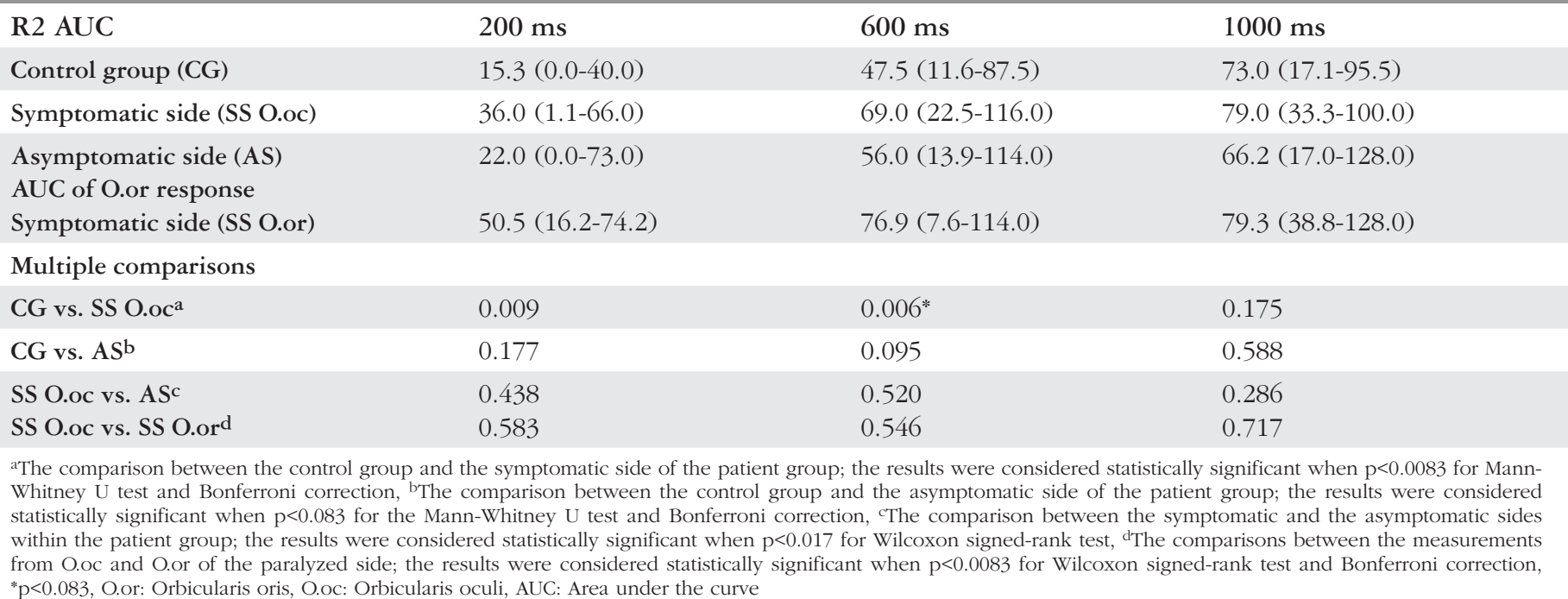


and R2 obtained on the symptomatic side in patients with PFS were longer than those of the asymptomatic side and those of the control group, and the R2 AUC was reduced on the symptomatic side of the patient group.

Among other factors, one factor affecting the severity of dysfunction of the facial nerve or development of synkinesis is the severity of the initial axonal damage (1). Kanaya et al. (20) reported that patients with an electroneurography value of $10 \%$ or more had a greater risk of developing facial synkinesis in the recovery phase of facial palsy. The clinical and electrophysiologic findings of BR following a single stimulus in our study supported the previous findings in the literature. There were residual weakness and substantial axon loss after the initial axonal damage in patients who developed synkinesis.

The study of BR, a multisynaptic reflex in the brainstem, provides clues about the pathogenesis of diseases related to the facial nerve. The electrical stimulation of the supraorbital nerve results in an early (R1) and a late bilateral (R2) response over the O.oc muscle $(21,22)$. The changes of R2 AUC and recovery curve in facial nerve-related aberrant movement disorders have been studied by numerous authors $(10,12,15,16,17,19,23,24)$. The ultimate result is that the excitability of $\mathrm{R} 2$ is increased on both sides.

Considering the O.or muscle, stable responses are not always expected following supraorbital stimulation in all healthy subjects. In hemifacial spasm, which is also characterized by synkinesis on the unilateral facial nerve-innervated muscles, two responses over the O.or were obtained after supraorbital electrical stimulation (25). The response with a latency similar to $\mathrm{R} 1$ was more stable compared with the late response obtained in a previous study (14). In another study on patients with HFS, an O.or response following supraorbital simulation with onset latencies similar to R2 was also reported (26). Although we observed an $\mathrm{R} 1$-locked response in some patients in our cohort, we did not include it in the analysis. The O.or response following supraorbital stimulation was previously studied in patients with idiopathic, clinically complete Bell's palsy and the authors concluded early and late components of the O.or were elicited after 12 days in patients with good recovery, whereas the responses were either absent or diminished in amplitude in patients with poor recovery (27). Moreover, another study of the O.or response in patients with PFS was performed by Eekhof et al. (28). In that study, the O.or response with R2 latency in healthy subjects was reported to be low-amplitude compared with R2 over the O.oc, whereas it was high in amplitude in patients with hemifacial spasm or post-facial synkinesis. The authors suggested that the results indicated a loss of inhibitory cortical control on the facial motor neuron pool innervating the O.or muscle. Similarly, the O.or response, which we described here, was identical to R2 in both magnitude and latency, suggesting an electrophysiologic counterpart of lateral spread. On the contrary, responses over the posterior auricular muscle (PAM) showed synkinetic spread in the presence of synkinetic spread of BR in patients with PFS (29). The authors explained this finding by the government of the PAM by a smaller nucleus that demonstrated a different behavior compared with O.oc motoneurons. Based on these previous findings, we may suggest that the behavior of the O.or nucleus after PFP resembles that of the O.oc nucleus.

The excitability of the R2 pathway was increased on the symptomatic sides of our cohort confirming the previous literature on the subject. The pattern and behavior of O.or excitability, the so-called lateral spread response, followed the excitability of BRR2. We found no significant difference between the percentage recovery obtained over the O.oc and O.or muscles. The similar recovery characteristics, early and high recovery, observed in these two muscles indicated that the excitability of the circuit that innervated the O.or muscles was also increased $(11,30)$. Thus, there may be similar hypotheses in explaining this finding: (i) excitability of O.or motoneurons may be increased in the recovery phase after PFP, or (ii) ephaptic transmission or regeneration from facial nerve fibers innervating the O.oc to fibers innervating the O.or may contribute to lateral spread and the increased excitability of the motor pathway to the O.or.

There is a somatotopy, a fine organization of facial nerve subnuclei within the facial motonucleus in the brainstem (31). It is widely known that the somatotopic organization is disrupted after PFP. In a rat study, after injuring and repairing facial nerve, axons projected to incorrect peripheral muscle groups, and aberrant branches innervated different subdivisions of the facial nerve (32). Thus, aberrant innervation of the O.or muscle by the O.oc nucleus might contribute to synkinesis and increased excitability. However, a similar aberrant regeneration at more distal levels may also result in a similar excitability pattern. Ogawara et al. (33) showed that injection of botulinum toxin to the O.oc muscle markedly alleviated spasms in the O.or muscle and concomitantly reduced the excitability of O.or neurons in hemifacial spasm. They suggested that skin or muscle afferent volleys via the trigeminal nerve enhanced the excitability of facial nerve motoneurons. In another study, it was hypothesized that filtering of facial sensory input at the brainstem was decreased in PFS (34). Thus, trigeminal contribution should not be ignored in patients with synkinesis. The possibility that the altered sensory input might increase the excitability of the motoneurons of the O.oc and O.or must be considered, which may warrant further analysis. Thus, although the excitability of the O.or motor pathway is increased in PFS, we should stress that our study is not able to differentiate between possible underlying factors in PFS.

In patients with peripheral facial paralysis, the lower facial motor cortex contralateral to the paretic side shows two distinct patterns: enlargement of the adjacent hand motor area, and an increase in the motor output to the intact perioral muscles from the lower facial motor area $(35,36)$. Studies showed that sensitization in polysynaptic pathways of the BR and an increase in excitability of facial motor neurons led to the pathophysiologic mechanism. In the event of axonal damage, the regeneration activity that starts in the following weeks may result in clinical-subclinical hyperactivity on both the paralytic side and the non-paralytic side with abnormal axonal branching and improper target innervation $(2,37)$.

The risk of developing synkinesis is high after between 6 and 12 months, even in fully recovered patients with PFP (38). The mean disease duration was longer in our group, we did not examine all patients when synkinesis was about to start. A series of investigations in patients with the potential to develop PFS may be interesting.

\section{Study Limitations}

In addition to the above-mentioned limitations, one other limitation of this study was the absence of O.or recordings on 
the asymptomatic side or in healthy subjects. We did not record it because the primary purpose of the study was to examine the excitability of motor circuitry only on the synkinetic side. There is a need for BR studies in patients with PFP with and without synkinesis to investigate the similarities between the excitability changes in the motor circuitry innervating the O.oc and O.or muscles and their possible underlying mechanisms.

\section{Conclusion}

Based on the data from this study, we suggest that the recovery curves recorded on the O.oc and O.or muscles in PFS are similar and thus the excitability changes of facial motoneurons and brainstem interneurons mediating motor pathway of these muscles have similarities.

\section{Ethics}

Ethics Committee Approval: Bahcesehir University Clinical Research Ethics Committee (protocol number: 2019-06/08, date: 20.03.2019).

Informed Consent: All subjects gave written informed consent.

Peer-review: Externally and internally peer-reviewed.

\section{Authorship Contributions}

Surgical and Medical Practices: F.Y., R.İ, A.G., M.K., Concept: F.Y., R.İ., A.G., M.K., Design: F.Y., R.İ., A.G., M.K., Data Collection or Processing: F.Y., R.İ., A.G., Analysis or Interpretation: F.Y., R.İ., A.G., Literature Search: F.Y., R.İ., A.G., Writing: F.Y., R.İ., A.G., M.K.

Conflict of Interest: No conflict of interest was declared by the authors.

Financial Disclosure: The authors declared that this study received no financial support.

\section{References}

1. Valls-Solé J. Facial palsy, postparalytic facial syndrome, and hemifacial spasm. Mov Disord 2002;17 Suppl 2:S49-S52.

2. Valls-Solé J, Montero J. Movement disorders in patients with peripheral facial palsy. Mov Disord 2003;18:1424-1435.

3. Baker RS, Stava MW, Nelson KR, et al. Aberrant reinnervation of facial musculature in a subhuman primate: a correlative analysis of eyelid kinematics, muscle synkinesis, and motoneuron localization. Neurology 1994;44:2165-2173.

4. May M. Facial nerve paralysis. In: Paparella MM, Shumrick DA, Gluckman JL, Meyerhoff WL (eds). Otolaryngology. Philadelphia: WB Sauders C, 1991:1097-1136.

5. Moran CJ, Neely JG. Patterns of facial nerve synkinesis. Laryngoscope 1996;106:1491-1496.

6. Cossu G, Valls-Sole J, Valldeoriola F, et al. Reflex excitability of facial motoneurons at onset of muscle reinnervation after facial nerve palsy. Muscle Nerve 1999;22:614-620

7. Eviston TJ, Chong LSH, Kwai NCG, Clark JR, Krishnan AV. Altered axonal excitability properties in facial palsy. Muscle Nerve 2018;57:268-272.

8. Hu S, Wub Y, Li C, et al. Increasing functional connectivity of the anterior cingulate cortex during the course of recovery from Bell's palsy. Neuroreport 2015;26:6-12.

9. Sun W, Feng W, Lu H, Gong S. Synaptic plasticity in the facial nucleus in rats following infraorbital nerve manipulation after facial nerve injury. Eur Arch Otorhinolaryngol 2016;273:3135-3142.

10. Valls-Sole J. Electrodiagnostic studies of the facial nerve in peripheral facial palsy and hemifacial spasm. Muscle Nerve 2007;36:14-20.

11. Nielsen VK. Pathophysiology of hemifacial spasm: I. Ephaptic transmission and ectopic excitation. Neurology 1984;34:418-426.
12. Eekhof JL, Aramideh M, Speelman JD, Devriese PP, Ongerboer De Visser BW. Blink reflexes and lateral spreading in patients with synkinesis after Bell's palsy and in hemifacial spasm. Eur Neurol 2000;43:141-146.

13. Öge AE, Yazici J, Boyaciyan A, et al. Magnetic stimulation in hemifacial spasm and post-facial palsy synkinesis. Muscle Nerve 1993;16:11541160.

14. Öge AE, Yayla V, Demir GA, Eraksoy M. Excitability of facial nucleus and related brain-stem reflexes in hemifacial spasm, post-facial palsy synkinesis and facial myokymia. Clin Neurophysiol 2005;116:1542-1554.

15. Kimura J, Rodnitzky RL, Okawara SH. Electrophysiologic analysis of aberrant regeneration after facial nerve paralysis. Neurology 1975;25:989993.

16. Valls-Sole J, Tolosa ES, Pujol M. Myokymic discharges and enhanced facial nerve reflex responses after recovery from idiopathic facial palsy. Muscle Nerve 1992;15:37-42.

17. Syed NA, Delgado A, Sandbrink F, et al. Blink reflex recovery in facial weakness. An electropysiologic study of adaptive changes. Neurology 1999;52:834-838.

18. Sahin S, Yaman M, Mungan SO, Kiziltan ME. What happens in the other eye? Blink reflex alterations in contralateral side after facial palsy. J Clin Neurophysiol 2009;26:454-457.

19. Nakamura K, Kashima K, Koike Y. Blink reflex excitability recovery curves in patients with dysfuncions after facial nerve palsy. ORL J Otorhinolaryngol Relat Spec 1999;61:10-15.

20. Kanaya K, Ushio M, Kondo K, et al. Recovery of facial movement and facial synkinesis in Bell's palsy patients. Otol Neurotol 2009;30:640-644.

21. Aramideh M, Ongerboer De Visser BW. Brainstem reflexes: electrodiagnostic techniques, physiology, normative data, and clinical applications. Muscle Nerve 2002;26:14-30.

22. Cruccu G, Deuschl G. The clinical use of brainstem reflexes and handmuscle reflexes. Clin Neurophysiol 2000;111:371-387.

23. Maeyama H, Aoyagi M, Tojima H, et al. Electrophysiological study on the pathology of synkinesis after facial nerve paralysis. Acta Otolaryngol Suppl 1994;511:161-164.

24. Valls-Sole J, Tolosa ES. Blink reflex excitability cycle in hemifacial spasm. Neurology 1989;39:1061-1066.

25. Montero J, Junyent J, Calopa M, Povedano M, Valls-Sole J Electrophysiological study of ephaptic axono-axonal responses in hemifacial spasm. Muscle Nerve 2007;35:184-188.

26. Choi SI, Kim MW, Park DY, Huh R, Jang DH. Electrophysiologic investigation during facial motor neuron suppression in patients with hemifacial spasm: possible pathophysiology of hemifacial spasm: a pilot study. Ann Rehabil Med 2013;37:839-847.

27. Manz F, Schenck E. Orbicularis oculi reflexes and evoked response of orbicularisoris muscle in Bell's palsy. A prognostic study (author's transl). J Neurol 1975;210:271-281

28. Eekhof JL, Aramideh M, Speelman JD, Ongerboer de Visser BW. Orbicularis oculi and Orbicularis oris reflexes in blepharospasm and torticollis spasmodica during spasm-free intervals. Eur Neurol 2001;46:75-78.

29. Kiziltan ME, Gündüz A, Sahin R. Auditory evoked blink reflex and posterior auricular muscle response: observations in patients with HFS and PFS. J Electromyogr Kinesiol 2010;20:508-512.

30. Ferguson JH. Hemifacial spasm and facial nucleus. Ann Neurol 1978;4:97103.

31. Asahara T, Lin M, Kumazawa $Y$, et al. Long-term observation on the changes of somatotopy in the facial nucleus after nerve suture in the cat: Morphological studies using retrograde labeling. Brain Res Bull 1999;49:195-202.

32. Choi D, Raisman G. Somatotopic organization of the facial nucleus is disrupted after lesioning and regeneration of the facial nerve: the histological representation of synkinesis. Neurosurgery 2002;50:355-362.

33. Ogawara K, Kuwabara S, Kamitsukasa I, et al. Trigeminal afferent input alters the excitability of facial motoneurons in hemifacial spasm. Neurology 2004;62:1749-1752.

34. Kiziltan ME, Gunduz A. Reorganization of sensory input at brainstem in hemifacial spasm and postparalytic facial syndrome. Neurol Sci 2018;39:313-319.

35. Liepert J, Oreja-Guevera C, Cohen LG, et al. Plasticity of cortical hand muscle representation in patients with hemifacial spasm. Neurosci Lett 1999;272:33-36. 
36. Rijntjes $M$, Tegenthoff $M$, Liepert JG, et al. Cortical reorganization in patients with facial palsy. Ann Neurol 1997;41:621-630.

37. Manca D, Munoz E, Pastor P, Valldeoriola F, Valls-Sole J. Enhanced gain of blink reflex responses to ipsilateral supraorbital nerve afferent inputs in patients with facial nerve palsy. Clin Neurophysiol 2001;112:153-156.
38. Fujiwara K, Furuta Y, Nakamaru Y, Fukuda S. Comparison of facial synkinesis at 6 and 12 months after the onset of peripheral facial nerve palsy. Auris Nasus Larynx 2015;42:271-274. 